msit

WICHITA STATE

UNIVERSITY

\section{Wichita State University Libraries} SOAR: Shocker Open Access Repository

Donald L. Gilstrap

University Libraries

\title{
Dissipative Structures in Educational Change: Prigogine and the Academy
}

Donald L. Gilstrap

Wichita State University

\section{Citation}

Gilstrap, Donald L. 2007. Dissipative structures in educational change: Prigogine and the academy. -International Journal of Leadership in Education: Theory and Practice; v.10 no.1, pp. 49-69.

A post-print of this paper is posted in the Shocker Open Access Repository: http://soar.wichita.edu/handle/10057/6944 


\section{Dissipative structures in educational change: Prigogine and the academy}

Donald L. Gilstrap

This article is an interpretive study of the theory of irreversible and dissipative systems process transformation of Nobel Prize winning physicist Ilya Prigogine and how it relates to the phenomenological study of leadership and organizational change in educational settings. Background analysis on the works of Prigogine is included as a foundation for human inquiry and metaphor generation for open, dissipative systems in educational settings. International case study research by contemporary systems and leadership theorists on dissipative structures theory has also been included to form the interpretive framework for exploring alternative models of leadership theory in far from equilibrium educational settings. Interpretive analysis explores the metaphorical significance, connectedness, and inference of dissipative systems and helps further our knowledge of human-centered transformations in schools and colleges.

\section{Introduction}

Over the course of the past 30 years, educational institutions have undergone dramatic shifts, leading teachers and administrators in new and sometimes competing directions. We are all too familiar with rising enrolments and continual setbacks in financial resources. Perhaps this has never been more evident, particularly in the USA, than with the recent changes in educational and economic policies. These policies have left schools and universities scrambling for money lost from state coffers while education boards even ponder the privatization of public institutions. The now ubiquitous use of technology has provided a significant catalyst for redefining educational roles, workflows, and processes, while students have higher expectations for the delivery of educational services in non-traditional formats. Organizational restructuring and redefined job skills are now at the forefront of institutional planning, yet we are often- times left with no real vision of where our schools and colleges are headed.

In order to grasp the vivid realities for responding to educational change in this new century, some hypothetical assumptions about the organizational structures of systems of education may be appropriate. Under the umbrella of administrative policies based on classical mechanics, humans operate in a system of controlled order where deterministic and linear philosophies are defining components of organizational function. The concept of scientific time management in the evaluation of educational services by high-level decision makers is, albeit altered, as pervasive in the beginning of this century as it was during much of the twentieth century. 
Even when teachers and administrators desire better and higher-level forms of educational evaluation, they are frequently forced to use externally prescribed assessment tools that measure only the value and performance of students in terms of quantifiable outcomes based on occasionally arbitrary measures. This, perhaps, can be evidenced in the USA with the 'No Child Left Behind Act', where state educational agencies are now required to justify student performance almost wholly through the use of standardized testing. In educational leadership, there seems to be a dualism between theory and practice, since we speak of methodological and paradigmatic shifts. However, we continue to focus on deterministic methods that can never replicate human models, since we are unable to control for all of the dependent variables involved in human experience (Gemmill and Smith 1985). As Goeppinger 2002: 77) notes, we 'seem to have fallen prey to our deductive, empirical nature, attempting to break down the parts of a complex thriving whole to the attributions of one or more individuals'. Educational policy makers and administrators also tend to utilize organizational re-engineering and strategic planning models that help to perpetuate these problems. Oftentimes, organizational structures are changed within schools behind the language of new leadership or management theories without actual shifts in administrative philosophies (Gale and Densmore 2003). Equally, schools and colleges continue to implement long-range planning models, but educational leaders are unsure about whether their successes can accurately be measured over extended periods of time (Birnbaum 2000). $\backslash 17 \mathrm{e}$ also function in bureau- cracies that are susceptible to attempts to preserve the longstanding hierarchical structures of our institutions at the expense of losing sight of our overall educational vision (Becher and Trowler 2001). Teachers and administrators are frequently mandated to provide services that are largely predetermined by conflicting external sources and that can some- times omit the value of the internal knowledge and experience of highly qualified teachers and administrators (Birnbaum 2000). When these individuals attempt to implement transformative changes, the grip of transactional leadership is strong enough to drive schools and colleges towards near equilibrium environments where mediocrity overshadows creativity (Friedman 2004).

We might also question if educational institutions actually operate in a framework in which deterministic models try to control disorder. As Pullan (2001: 110) reveals, K-12 school districts might already be seeing far from equilibrium conditions:

In schools, for example, the main problem is not the absence of innovations but the presence of too many disconnected, episodic, piecemeal, superficially adorned projects. The situation is worse for schools than for businesses. Both are facing turbulent, uncertain environments, but schools are suffering the additional burden of having a torrent of unwanted, uncoordinated policies and innovations raining down on them from hierarchical bureaucracies.

So how can educational leadership evolve to a view that considers the complexities of these competing environmental issues? Fullan (2001) has consistently argued that business and education have much to learn from each other. Therefore, one suggestion might be to reinvestigate the case study research that has been performed on dissipative structures theory and how these studies might change the way we look at classical leadership theory as a basis for decision-making, organizational structure, and human interaction. 
In educational research, we recognize that there are limits to deterministic models when describing human interaction and experience, but we struggle with the paradox that these models continue to int1uence our epistemological framework for leadership theory. Scientists throughout the twentieth-century, however, searched for alternative and nonlinear views to address the anomalies of classical theories generated during the Enlightenment. In this article, I would like to focus on the work of Nobel Prize winner, Ilya Prigogine, who in 2003 passed from the scientific community. During the last part of the twentieth century, he had a profound effect on the establishment of dissipative structures theory-one branch of the complexity or 'new' sciences-which have int1uenced the works of several contemporary scientists, including Eric Jantsch (1981) and Gregoire Nicolis (1989). The importance of Prigogine's research and epistemological curiosity has led to the creation of over 30 complexity institutes around the world, with Prigogine himself having held director- ships at the Instituts Internationaux de Physique et de Chimie in Belgium and the Ilya Prigogine Center at the University of Texas in Austin. Equally, Prigogine has had a profound impact on the development of systems models of leadership (Schwarz 1997, Checkland 1999, Senge 1990, 2004).

Prigogine critiqued the continued use of classical mechanics theories to describe human interaction, since 'the external universe appeared to be an automation following deterministic causal laws, in contrast with the spontaneous activity and irreversibility we experience' (Prigogine and Stengers 1984: 311). Prigogine's research, therefore, brings several exciting yet confusing implications for understanding the world around us, as he proposed a new focus on transformatory change for events experienced in and among living systems. This article provides a background on the works of Prigogine as a foundation for human inquiry and metaphor generation for open, dissipative systems in educational settings. International case study research by contemporary systems and leadership theorists on dissipative structures theory has also been included to strengthen the connections between dissipative structures theory and the human world while generating an interpretive framework for exploring alternative models of leadership theory in far from equilibrium educational settings. It is the purpose of this article, therefore, to analyse and describe through an interpretive lens the metaphorical significance, connectedness, and inference of these models which might help further our search for knowledge on human-centered transformations of educational institutions and the people who teach and lead within them.

\section{Understanding Prigogine}

Developing a dissipative systems approach to educational leadership

For the scope of this article, it would be impossible to explore comprehensively a scientific analysis of Prigogine's life work on dissipative structures. I feel it is important, however, to convey at least some of Prigogine's basic principles and transmute this knowledge in ways that are metaphors for the development of leadership theory. Major concepts that will be addressed in this section are the irreversible process, entropy, self-organization, bifurcation, and how each of these leads to transformative changes within systems.

As very basic examples, irreversible processes would include heat or electrical conductivity, diffusion of matter, and chemical reactions where the beginning system is changed irreversibly 
into its final product during the process; sometimes even at the element level. As physicist Tony Rothman (1997: 26) explains metaphorically, 'eggs can be scrambled but not the reverse'. If we explore this metaphor further, once the yolks have been mixed into the whites, it is impossible to change them back to their original state. The final product contains all of the original materials, and additionally might contain elements that have been added externally, but there is no returning to the original substance.

Entropy is another critical factor that helps us understand the dynamics of life systems. Entropy is the measure of unavailable energy in relation to random disorder, or chaos, in a system process. Prigogine $(1967,1980)$ found internal irreversible processes consistently perform in manners that try to lower the effects of entropy. Even though there are changes occurring throughout a process which cause increases in entropy-such as temperature and electrical fluctuations-these internal irreversible processes eventually return to a stable state, sometimes transformed to an even higher level of development (Prigogine 1967, 1980).

In Franz Being to Becoming (1980), Prigogine expanded his research on thermodynamics and developed one of his principle theories: Order through Fluctuations, or rather self-organization. Dissipation in living systems can be defined as a system slowly expending or scattering energy and matter over time as a means to maintain or even increase the complex structure of the system. However, external or internal tensions can create system fluctuations and lead to instabilities of a chaotic and unpredictable nature. In our western culture, we tend to view the term chaos as a pejorative and as something we certainly would want to avoid in organizational settings. Yet, interestingly enough, 'chemical instabilities involve long-range order through which the

system acts as a whole' (Prigogine 1980: 104). Moreover, as part of the self-organization process, systems going through bifurcation rely on their history in order to arrive at their final composure, known as self-referencing. In effect, a system in chaos actually contains simultaneous order and disorder where by each part of the system acts collaboratively and historically to bring about system-wide order.

It might seem paradoxical that order arises from chaos, but dissipative systems are even more complex than this. Order through Fluctuations can be observed through bifurcations, where a bifurcation constitutes a split or division from the original system state. As tension or instability increases in a system moving away from equilibrium, the system bifurcates, sometimes involving transformative change in which the end result is a not only different than the original but has evolved into two separate and stable, higher-order systems. In dissipative structures, the individual parts of the system actually self-organize in an effort to generate new, adaptive solutions to instabilities that move systems toward bifurcation.

The fluctuations that appear before a bifurcation were observed previously in microscopic physics but had been dismissed, since they tended to defy the structured control of classical mechanics. However, Prigogine (1980: 132) showed that 'near bifurcations they [fluctuations] play a critical role because there the fluctuation drives the average. This is the very meaning of the concept of order through fluctuations'. Systems tend to generate small fluctuations spontaneously, yet the closer the system is to a bifurcation, the greater the chance for the fluctuation to be large and create 'new nonequilibrium transitions not predicted by the 
phenomenological laws of evolution' (Prigogine 1980: 147). Returning to the metaphor of dissipative structures in educational environments, this implies that a school changes not only due to stress brought on by external factors but also by internal stress. Equally, this suggests that small changes in schools and colleges over time can culminate into transformative institutional change.

In summarizing Prigogine's theories, we can construct metaphors about human experience and organizational dynamics in educational settings that relate to dissipative system views of biological and chemical processes in our human environment. Dissipative structures imply that as an organization gains tension or stress, a split or division can occur from which one or more higher order systems arrive. As metaphors for educational leadership from a human perspective, fluctuations in educational environments provide catalysts for change. Bifurcations constitute a split from our old organizational structures and have the potential to lead institutions and individuals to higher levels of development. Further, self-organization and self-referencing act as the human dynamics that lead to bifurcations. In the next few sections, I will discuss how these metaphors can emerge in educational settings, providing a different lens for viewing leadership theory as a human experience-centered phenomenon.

\section{Dissipative structures and the human world}

The structures of irreversible processes in science are influenced by entropy, fluctuations, selforganization, and bifurcation, and we can see how these concepts can be used as metaphor building constructs for educational leadership. It can be argued that the human world is much different from the natural world, and the incorporation of higher-level human beings into the general concept of living systems might leave us with an uneasy view of our connection to the biological world. However, Prigogine's work 'was not to confine himself to mathematical or chemical technicalities but to consider the epistemological incidences of these scientific developments' (Schwarz 1997: 22). Moreover, Stacey (1992b) and Pascale, Millemann and Gioja (2000) contend that the ideas and constructs of Newton's classical mechanics were used as the theoretical framework for the economic theory that was transposed into the leadership and management theories of the nineteenth and twentieth centuries.

In effect, predictive models of the scientific world have formed the basis for the evolution of pure and applied leadership theory. However, scientists throughout the twentieth century have proven that the universality of classical mechanics does not hold in dissipative and chaotic systems (Prigogine 1961, 1967, 1980, Jantsch 1981, Applegate et al. 1985, 1986, Sussman and Wisdom 1988, 1992, Waldrop 1992, Peterson 1993, Touma and Wisdom 1993, Rothman 1997, Wisdom 1998, Karpov et al. 2000). Although classical mechanics models serve valuable purposes, many educational and leadership researchers now challenge the limitations of these same types of models applied universally in the social sciences, suggesting that human experience and interaction are oftentimes too complex to be measured predictively with any long-term certainty. They argue that nonlinear models like dissipative structures theory allow us to reinvestigate the successes and failures of a classical framework for leadership theory, discovering new correlations between irreversible systems and human interaction while reconciling the plurality of postmodernism, poststructuralism, deconstructionism, and interpretivism (Gemmill and Smith 1985, Sawada and Caley 1985, Doll 1986, 1987, 1993, 
Stacey 1992a, 1992b, 2003, Blair 1993, Smith and Comer 1994, Wheatley 1994, Fleener 1995, 2002, Nadler, Shaw and Walton 1995, Van Olffen and Romme 1995, Jenner 1998, Bass 1998, Macintosh and MacLean 1999, 2001, O'Sullivan 1999, Lichtenstein 2000, Pascale, Millemann and Gioja 2000, Fullan 2001).

In addition to the epistemological references Prigogine's work provides for leadership theory, MacIntosh and MacLean (1999: 305) see a higher level characteristic markedly distinguishing our human world from the scientific world in the incorporation of dissipative structures theory:

Organizations have the capacity to bring about a change in archetype through consciously creating the conditions in which successful transformation can occur. Those within the organization can, to some extent, choose the primary rules which govern the deep structure.

Dissipative structures theory, therefore, relies on our existence and experiences as human beings. It provides us with an opportunity to reinterpret our historical and theoretical relationship with the natural world through what Prigogine and Stengers (1984) and Prigogine (1997) describe as, 'man's new dialogue with nature'. This provides us with the conscious ability to reference the histories of our schools and colleges-while developing system parameters during transformative change-which increases our likelihood of successful educational changes.

\section{The evolution of dissipative structures in systems theory}

Systems theorists have also incorporated dissipative structures theory into contemporary research for many years. After famed biologist von Bertalanffy's (1973/1968) ground breaking work, General System Theory, Ackoff $(1981,1994)$ brought us methods for the creation of democratic corporations which added to the foundation for the democratic movement in educational leadership. Checkland (1999) focused more deeply on the works of Prigogine (1980) and Jantsch (1981) in the 're-invention' of systems theory, known as soft systems methodology. Senge (1994 , 2004) is perhaps the most well-known systems theorist in management and leadership literature, arguing for learning organizations as the catalyst for industry success-ideas centred on dissipative structures philosophy.

Distinguishing between controlled and nonlinear environments, Newman (2000: 3) describes first-order systems change as slow and incremental transitions over time, 'but it does not involve fundamental changes in strategy, core values, or corporate identity'. Conversely, she illustrates second-order systems change with language such as 'transformational', 'an organizational metamorphosis', and that change is brought on by either external or internal influences (Newman 2000: 604). In dissipative structures theory, first-order change relies primarily on negative feedback mechanisms which keep an organization close to equilibrium (Stacey 2003); in effect, on a linear and deterministic path. As a transactional philosophy (Bass 1998, Bums 1979), we might recognize this leadership strategy through the old adage of 'keeping the ship on course'. If the school moves away from its proscribed strategic plan, we apply dampening mechanisms that bring people back to predetermined organizational paths. In this manner, the degree of change is kept at a minimum in order to keep from disturbing the equilibrium of the organization. 
Although there might be times when it seems fitting to control order in an organization by moving it towards equilibrium, as is the case with first order systems change, there may be unexpected consequences from this approach. Returning to Prigogine's description, equilibrium implies that the decay of a system is imminent (Prigogine 1984, Stacey 1992b, 2003, Pascale, Millemann and Gioja 2000, Fullan 2001). Entropy will slowly dissipate from the system until internal potential energy is at a low level, and changes in the external environment make it impossible for the system to take in enough energy to adapt to it. In systems theory, this is similar to Ashby's (1956) Law of Requisite Variety, where variety within a system is critical for its survival, and, conversely, the more this variety is controlled the more it starts to be destroyed. Quite frequently we find examples of this when we have become so accustomed to performing the same process-such as budgeting, planning, or assessment-tl1at we continue to try and find ways to make these prescribed processes work better, even if the external environment has changed or has eliminated the need for the process altogether (Macintosh and MacLean 1999, Pascale, Millemann and Gioja 2000, Stacey 2003). By using the lens of classical mechanics in educational leadership, we are trying to bring our institutions toward equilibrium; we are trying to control organizational turbulence. As a result, we create situations where we waste energy and resources, trying to make a process work while inhibiting our ability to recognize the need to change it.

\section{Moving away from control structures in educational leadership}

In transferring this knowledge to the educational community, many leadership theorists now argue that we can no longer avoid deeper investigations into dissipative structures theory in educational leadership because it seems to be an integral aspect of how humans interact with each other while experiencing the world. Equally, a classical mechanics approach to leadership places the foci of educational administration almost completely on controlling disorder and leads to significant opportunity costs, wasted resources, and the possible dissolution of the institution. Consequently, Wheatley (1994) contends that the process-oriented structures of the natural world are much more closely related to human experience than the mechanistic control forces we try to incorporate in organizational life:

We have created trouble for ourselves in organizations by confusing control with order ... If organizations are machines, control makes sense. If organizations are process structures, then seeking to impose control through permanent structure is suicide. (Wheatley 1992: 22-23)

In a more radical interpretation of living systems, Pascale, Millemann and Gioja (2000) see our reluctance to move away from these mechanisms for controlling turbulence as extremely dangerous for the long-term survival of organizations:

Equilibrium is a precursor to death. When a living system is in a state of equilibrium, it is less responsive to changes occurring around it. This places it at maximum risk (Pascale, Millemann and Gioja 2000: 6)

Furthermore, Carr-Chellman (2000) sees the need for dissipative structures theory as the most critical and challenging aspect of the new century. In her view, if we continue to implement mechanisms for controlling order, 'this is precisely the sort of reaction which will spell death through entropy to the current system of public education' (Carr-Chellman 2000: 35). 
The ideas of dissipative structures theory, therefore, transcend many of the control mechanisms that move people towards equilibrium, and, consequently, stifle educational growth and development. Equally, dissipative structures theory, in combination with many other postmodern and poststructuralist philosophies, moves leadership theory towards an investigation of the processes of human interaction (Doll 1993, Fleener 2002). The next sections of this paper explore ways that dissipative structures theory in the natural world can be implemented or can emerge in educational settings through self-organization, learning environments that foster complexity, team-based and self-referenced approaches to leadership, positive and negative feedback loops, and individual transformation.

\section{Self-organization and self-referencing}

International case studies on the successes and failures of institutions in transition

Another fundamental aspect of dissipative structures theory is the concept that biological systems bring knowledge of their past into a transformed system, or what Prigogine and Stengers (1984) and Prigogine (1980) describe as self-referencing. O'Sullivan (1999) compares this process of self-referencing with Maturna and Varela's (1980) term 'autopoiesis,' where life continually seeks out ways of improving on old forms in a creative manner that preserves elements of the older structures. "The underlying structures of organisms and species have the imprint of habits from the past that allow natural habits to be formed by the organism's structure with its history,' and, consequently, these organisms will act in a manner associated with this history. (O'Sullivan 1999: 210, 239). A collective unconscious if you will, human experiences and interactions are more complex than those of biological systems, so we as educators have the luxury of either choosing to bring this institutional history with us or abandon it in favour of an entirely new system (Gimmell and Smith 1985). If we return to Prigogine's work on self-organization in dissipative structures, we can identify areas of the human environment where these types of events also take place.

An analysis of institutional transformations in former Soviet countries in Central and Eastern Europe during the 1990s can provide an accurate view of changes in dissipative structures at their extremes. After the collapse of the Soviet political and economic structure, people working in institutions of all types were dramatically thrust from a world of slow-paced bureaucracy into a rapidly shifting and competitive world. Central planning had disappeared, fixed prices and currencies were subject to the global economy, banking systems fell under the purview of capital markets, and educational institutions opened to a new realm of possible methodologies and organizational patterns (Newman 2000). These institutions' former values and core belief systems would doom them to rapid decay within the global economy if they did not establish new philosophies and priorities for the future.

Newman's (2000) research on former Soviet institutions identified self-organization and selfreferencing, key components of Prigogine's Order through Fluctuations, as critical factors of successful transformations in a global environment. Many managers and staff in former Soviet countries were left without self-organizing principles and self-referencing methods, and, consequently, they did not have the knowledge base, history, and available resources to succeed in restructuring their institutions. People in some organizations fell back on the trustworthy and 
secure practices of the past rather than address scenarios of what the future may or should bring. In these situations, employees attempted to harness chaos, forcing them towards the near equilibrium environment they once knew.

Some East European institutions also tried to 'mimic' successful organizations, particularly in the West, but were confronted with failure because they lacked similar resources or incorporated irrelevant strategies for change (Newman 2000). Again, drawing on Prigogine's Order through Fluctuations, successful and positive bifurcations cannot take place without the system having a distinct knowledge of its own history with which to refer in a nonequilibrium environment. Employees in these East European organizations attempted to borrow from the histories of other systems, leaving the former devoid of self-organizing reference points with which to base their own transformations. These actions subsequently led their organizations to fail in light of their new socio-politico environment.

Additionally, the capacity for self-organizing and self-referencing principles might exist in an institution, yet the pull toward equilibrium among employees is too strong. In their study of institutional change in East Germany during the early 1990s, Breu and Benwell (1999) found that middle managers and supervisors went through a developmental process of acceptance or rejection of change. At first, managers fell into states of passivity, because they felt they had no power to effect change. Some then realized the magnitude and requirements of the change and 'erupted into hyperactivity', where they began frantically instituting change policies and procedures with no real understanding of the whole organizational picture, known as unbounded instability in dissipative systems. After recognizing that they were failing, some of these managers began to second-guess themselves and were hesitant to institute any further changes, returning to an equilibrium-oriented philosophy. However, Breu and Benwell (1999) found that those who sought out new knowledge on the reasons for organizational change-and were able to integrate it with the knowledge of their organizational history-participated in individual transformations that moved them successfully into their new environment.

Equally, in Macintosh and MacLean's (1999, 2001) studies of UK corporations, dissipative structures them-y was applied in a radical effort to transform failing companies. Just as in many of the former Soviet institutions, employees in the UK firms exhibited an intense resistance to change. Employee desires to move toward equilibrium were so strong that the model had to be re-applied on successive attempts before organizational bifurcations started to take place.

We can infer from these case studies, therefore, that there are several implications for leading transformative changes in educational settings through the use of dissipative structures theory. Newman's (2000) analysis show us that to thrust rapid and comprehensive restructuring on an educational institution or simply to copy the existing organizational structures of successful institutions without any reference points or educational insight might leave us with results similar to those encountered by institutions in Central and Eastern Europe. Breu and Benwell's (1999) research illustrates stages of developmental confusion and acceptance those of us in education might face during dissipative change. Breu and Benwell's (1999) and MacIntosh and Maclean's (1999, 2001) studies reinforce the implicit knowledge that change is often difficult within organizations; that there will be both adopters and resisters. But how can leaders encourage self-organization and self-referencing in the work place? 


\section{Creating an environment for emergent dissipative structures}

Applying positive and negative feedback mechanisms to structure dissipative system parameters

There are many ways we can seek out the emergent properties of self-organization and selfreferencing found in dissipative structures theory and integrate it into our educational environments. Primarily, the use of positive and negative feedback mechanisms can move schools towards near-equilibrium or far-from-equilibrium conditions. When an educational institution begins incorporating a dissipative structures model, there is an underlying tendency to return to the way things were previously; to move toward equilibrium. At this point, teachers and administrators can promote the growth of a dissipative system by concentrating energy and resources to help individuals and teams grow and further establish the philosophy. Negative feedback loops, on the other hand, would dampen resources of those individuals who resist the changes brought about by a dissipative system. The application of positive and negative feedback loops is not implied to be a transactional, contingent reward system where an individual stands to gain or lose (Burns 1979); rather, this method is used to divert valuable energy and resources from equilibrium oriented units in an organization toward far from equilibrium teams.

There are also two schools of thought on whether to apply to these techniques to facilitate bifurcations or keep the organization near the edge of chaos. The 'edge of chaos' philosophy would encourage teachers and administrators to utilize these amplification and dampening mechanisms to help a school thrive at a far from equilibrium level that pushes toward the bifurcation point yet never quite reaches it. Likewise, if the level of stress or perturbation is significant enough to lead to a bifurcation, then it is necessary to apply enough negative dampening measures to back the school just close enough away from a bifurcation to prevent a chaotic episode (Pascale, Millemann and Gioja 2000).

Conversely, a pure dissipative structures philosophy argues that transformation takes place by pushing an organization into a chaotic cycle that eventuates bifurcation. In this manner, teachers and administrators would apply positive and negative feedback loops with the intent of causing a bifurcation that leads the organization to a potentially higher level of development

(MacIntosh and MacLean 1999, 2001). Each philosophy incorporates Prigogine's (1967, 1980) work: the former moves an organization toward a far from equilibrium state where selforganization takes place, and the latter results in an additional, transformative bifurcation. In essence, these positive and negative feedback loops are the external and internal factors placed on a system that allow or dampen a system's ability to dissipate energy.

Lichtenstein's (2000) case studies of self-organizing transformations in US corporations highlight the use of positive and negative feedback mechanisms to push institutions past 'the edge of chaos' to bifurcation. Institutional transformations can take place by either increasing or decreasing planning activities in relation to the resources available for change. If resources are unavailable yet planning activities increase (positive feedback), the resulting increase in stress, intensity, and tension will cause the organization to operate in a nonlinear state. When this happens, even the smallest transformative action can bring on system-wide change in an institution that is ready for it, and self-organization will begin if reference points to the 
organization's history are included. This analysis again echoes Prigogine's $(1967,1986)$ theory of Order through Fluctuations.

Feedback loops must be used with a few words of caution. Their overuse can lead most apparently to micro-management, where by teachers and administrators spend the majority of their time applying negative and positive feedback mechanisms. Stacey (1992) argues that the over-application of either of these methods actually drives an organization toward nearequilibrium conditions where leaders try to control the actions of individuals rather than facilitate the dynamics of groups. Stacey (1992: 54-55) sees a third option, known as

bounded or limited, far from equilibrium, in which behavior has a pattern, but it is irregular. Only when a system operates in this chaotic, fractal, far-from-equilibrium state is it continually creative in the sense that as its behavior is automatically fed back into the rule that generates it, different outcomes are always produced.

By returning to the concept of self-organization within nonlinear systems, educational administrators might even consider positive and negative feedback loops from a different perspective. Recognizing that educational institutions are quite commonly some of the most diverse organizations in the world, perhaps this diversity can act as a catalyst for the emergence of self-organizing positive and negative feedback mechanisms. Teachers and administrators must know when to let go of a situation and let the dynamics of a team or group determine the outcome rather than trying consistently to apply negative and positive feedback mechanisms. As Stacey (1992: 62) notes, 'chaos in its scientific sense is not utter confusion. It is constrained, rather than explosive, instability. It is a combination of order and disorder in which patterns of behavior continually unfold in irregular but similar forms' and, therefore, become a bounded instability. Therefore, the diversity of race, gender, age, academic background, and many more of the connected factors of human interaction, might in effect allow a team to apply its own feedback mechanisms and prevent runaway chaos.

\section{Dissipative group dynamics: self-organizing teams and increased flows of information}

At the micro level, perhaps one of the best ways for educational administrators to foster selforganization is through a team-based environment. Team-based structures are different from committee structures in that they tend to follow biological patterns of organization that more closely approximate natural human interactions. Some teams might exist semi-permanently to complete recursive processes. Other teams might be organized along functional areas and integrate with similar teams during project management cycles. Perhaps the most progressive self-organized and self-managing teams are those that arise spontaneously out of need for specific projects and disappear upon their completion (Yukl 2002).

Teams are also most adapted to organizations that are influenced by dissipative structures theory. Van Olffen and Romme (1995: 204) expand this argument, suggesting teams are critical components of self-organizing systems:

Teams can handle novel information faster and better than any other known human system. Thus, effective teams produce creative solutions-in the form of new ideas, strategies, products, 
technologies. As such, effective teams are units acting according to the image of dissipative selforganization.

Moreover, in their research on self-organization among graduate students in small group settings, Smith and Comer (1994) found that the groups who exhibited dissipative structures traits were more apt to handle and deal with change, particularly turbulent, than those groups who did not exhibit these traits. Furthermore, both Van Olffen and Romme (1995) and Smith and Comer (1994) argue that the self-organizing principles of teams provide the litmus test for group and dissipative structures effectiveness.

An interesting component of teams is that an interdependence between people emerges during spontaneous self-organization. Team members begin functioning at higher levels and collaborate in ways that facilitate increased innovation (Lichtenstein 2000). This does not imply that educational administrators should adopt a laissez-faire attitude towards leadership. Rather, leaders need to develop environmental parameters that maintain enough structure to keep the organization from slipping into unbounded instability that can lead to negative bifurcations. At the same time, educational administrators need to allow for enough structural freedom so that spontaneous self-organization takes place (Lichtenstien 2000), what Brown (2002) describes as 'local innovation' where people will create new ways to deal with the unforeseen.

An interesting component of teams is that an interdependence between people emerges during spontaneous self-organization. Team members begin functioning at higher levels and collaborate in ways that facilitate increased innovation (Lichtenstein 2000). This does not imply that educational administrators should adopt a laissez-faire attitude towards leadership.

Rather, leaders need to develop environmental parameters that maintain enough structure to keep the organization from slipping into unbounded instability that can lead to negative bifurcations. At the same time, educational administrators need to allow for enough structural freedom so that spontaneous self-organization takes place (Lichtenstien 2000), what Brown (2002) describes as 'local innovation' where people will create new ways to deal with the unforeseen.

As an example, having sufficient resources available to affect desired changes is a dilemma most of us face, but how can we focus our vision more closely on those existing resources that appear invisible? Lichtenstein (2000: 5) argues that nonlinear dynamics applied to the organization can solve this problem, finding 'new ways to utilize tangible and intangible resources that already exist in the firm'. In this case, an organization has been driven toward a far-from-equilibrium environment and has adapted. In educational settings where we have been most recently confronted with the competing tensions of internal and external resources and requirements, we can see how self-organizing teams can be beneficial in focusing our vision more closely on those existing resources that appear invisible while allowing for progress in a time when growth may be necessarily curtailed by our governing bodies due to financial exigency.

Increasing flows of information among teams and between individuals equally becomes necessary to facilitate self-organization through a learning-centred approach to communication. Prigogine $(1980,1997,2000)$ has shown that the information that flows into and within a dissipative system becomes the catalyst for eventual bifurcations. Using a metaphor for leadership theory, we can recognize the importance of creating an environment where information flows freely, motivating a desire to learn more about dissipative structures theory. 
Equally, the organization must be willing to deconstruct old processes while becoming receptive to a change-oriented philosophy that comes with increased communication channels (Gemmill and Smith, 1985). This is perhaps hardest at the point where there is the most turbulence, however.

Prigogine and Stengers (1984: 189) argue that when new components, such as information flows, are introduced into a stable system, they begin competing with the old structure:

If the system is "structurally stable" as far as this intrusion is concerned, the new mode of functioning will be unable to establish itself and the "innovators" will not survive. If, however, the structural fluctuation successfully imposes itself... the whole system will adopt a new mode of functioning: Its activity will be governed by a new "syntax".

Equally, we know oftentimes we are frustrated by our initiatives for change that are viewed skeptically and cynically by our colleagues. Gemmill and Smith (1985) concur with Prigogine's findings and show that organizations are also susceptible to slipping back to near-equilibrium conditions at this point in the change process. However, they argue that increasing information flows and communication channels surrounding the dissipative structures philosophy will give individuals a context within which they can view the organizational transformation. This encourages a desire to enter into a stage of uncertainty that will help them succeed in a nonlinear environment (Gemmill and Smith 1985).

It therefore becomes critical for teachers and administrators operating in open, nonlinear systems to foster information-rich environments to avoid slipping into entropy. Creating this environment can come in the form of web-based tutorials, brown bag lunches, town hall meetings, and joint team meetings. Instead of dictating strategic plans or road maps for future changes, educational administrators can present institutional concerns in ways that encompass dissipative structures theory and respond to changes in the internal and external environment. As one example, in their study of the bioengineering company, Monsanto, Pascale, Milillemann and Gioja (2000) found that the CEO, Robert Shapiro, adopted a dissipative structures approach to internal communication. Rather than circulating directives from the top down, Shapiro held town-hall meetings where members from several existing hierarchical levels of the company participated. Shapiro resisted giving employees solutions to problems, but rather he presented the problems in ways where he appeared to be 'thinking out loud'.

By approaching communication in this way, employees were driven into a state of disequilibrium, as their CEO presented no absolutes. Monsanto employees came away from these meetings with their own interpretations of what they had heard Shapiro say, and they met with each other to discuss their views of the meetings tempered with their own knowledge and experience with Monsanto (Pascale, Millemann and Gioja 2000). Shapiro's combination of teambased structures and open flows of communication became an effective dissipative system:

Straight uncensored talk about 'the way things really work around here' allows a lot of hidden conflict and frustration to surface in a constructive way. Having teams present their findings to one another sparks debate and dialogue. The atmosphere changes from a 'theater with performer' to a conversation among colleagues'. (Pascale, Millemann and Gioja 2000: 97) 
In this way, Monsanto employees highlighted Prigogine's concept of self-organization, as spontaneous opportunities arose for individuals to self-refer to their experiences while increasing the flow of information between individuals and groups.

Improved information flows and communication do not always lead to successful outcomes in dissipative structures organizations, and Prigogine (2000) reminds us that systemic bifurcations are not always positive. Stacey (1992b) warns of the negative aspects of bifurcations that can occur if non-linear group dynamics are not mentored effectively by leaders. He notes that in the business world, groups might tend to share a single vision-contributing to runaway chaos-since the group might lack someone to argue counter positions. The group then keeps charging forward, sometimes even faster than the organization is able to adapt. Stacey (1992b: 176) accurately describes, that the opposite effect exists in educational settings where 'the purpose of the group is as he or she defines it and that if he or she proposes an action, that action should be adopted-in other words, each individual believes in 'winning". This belief is supported in educational research by Becher and Trowler (2001), Lakoff (1992), and Tarule (1997), who find that our dysfunctional, disconnected, and erudite communication patterns limit our abilities to change our schools progressively. Thus, we effectively curtail information flows in our open systems of education.

Prigogine (2000) also suggests that the negative aspects of increases in information flows can be exacerbated by the rise in technologically-networked environments. Since there will be an infinite amount of new bifurcations due to an exponential increase in the communication channels of individuals, Prigogine (2000: 36-37) argues for proactive ways to deter a collective identity among group members and to continue to foster development in individuals:

As the population becomes more networked, there may be an opposite effect: the imperatives of the connected collective overwhelm the individual's ability to make choices. The future is not given. Especially in this time of globalization and the network revolution, behaviour at the individual level will be the key factor in shaping the evolution of the entire human species. Just as one particle can alter macroscopic organization in nature, so the role of individuals is more important now than ever in society.

These dilemmas will challenge leaders to think in new ways that incorporate self-organizing teams while overcoming the 'winning' philosophy inherent in educational settings; that utilize existing and future technologies for the benefit of communicating diverse ideas rather than collective identity; and that preserve the internal feedback mechanisms produced by the strength of individuals leading through self-managed teams. Therefore, the next section focuses on the most critical element of educational transformation-individuals- and how leaders can help facilitate transformative individual changes through a dissipative structures learning philosophy.

\section{Dissipative structures at the micro level}

The importance of individual reflection on educational transformation

When implementing second-order system changes, Newman (2000: 607) argues that it is necessary to facilitate second-order learning. This 'involves the search for new routines and schemas, rather than mastery of existing routines, and is most likely when aspirations are not met, when existing routines become ineffective, or when new information cannot be understood 
within the currently accepted behaviours'. Many of us are familiar with this dilemma in education, yet we are unsure how to break from the stagnation of near-equilibrium conditions by changing learning philosophies [theories].

Transformative learning theory has grown in the professional adult education literature for a number of years, and transformative learning in general relates uniquely to dissipative structures. In Prigogine's Order through Fluctuations, a system bifurcates to a new level of development as a result of external perturbation. The intended outcomes of transformative

learning are that learners reach higher levels of development, usually brought on by turbulence in their lives. The bifurcations of which Prigogine (1980, 1997, 2000) speaks are just that: transformative. Using a dissipative structures lens to view our educational environments assumes a transformative change in how we think and learn about educational institutions. As a result, personal transformation among individuals becomes critical in organizations operating in nonequilibrium environments.

Dissipative structures theory implies that recognizing system-wide details and how they interrelate is critical for understanding complex organizations. In dissipative structures theory, a focus on the individual becomes an important aspect of effective leadership theory, since farfrom equilibrium organizations rely so heavily on critical reflection by the individual

to arrive at positive bifurcations. This is similar to Burns' (1979, 2003) and Bass' (1998) theory of transformational leadership, where individual self-fulfilment leads to higher order group behaviour. Consequently, we can assume that we must generate new ideas on how we might open dialogues that lead to transformative individual growth. Nadler, Shaw and Walton's (1995) study of US corporations showed that leaders must resist delegating transformative strategies but rather actively work with staff during these transitions. Moos (2003: 29) also suggests this coleadership perspective in education, arguing that the leader stops leading other people and, rather, 'leads with other people'. Karpiak (2000) furthers this view, describing transformative learning as a shared experience among all the participants. These arguments reveal the emphasis teachers and administrators must place on their abilities to develop closer individual relationships with colleagues while adopting a teaching role that helps the educational community understand more about the process of teaching and learning. Moreover, these types of mentoring approaches help to break down the socio-ethnic tensions prevalent in many organizations, providing critical opportunities for the development of successful women and minorities whose professional growth is oftentimes viewed as tertiary (Carter 2002).

Transformation in the individual, however, is not a priori in our schools and colleges. Karpiak (2000) argues 'we cannot simply will ourselves to transform to higher stages of development'. She notes that individuals must be oriented towards tasks that inspire transformation, that they must be flexible in their attitudes towards understanding, and that they must resist seeking the easiest paths in the choices they make. This type of theory encourages a desire to enter into a stage of uncertainty that helps individuals succeed in a far-from-equilibrium environment (Gemmill and Smith: 1985).

Likewise, teachers and administrators must actively inspire colleagues through teacher-learner partnerships, as individuals deal with the transformative changes brought on by a turbulent organizational environment. 
Transformative learning entails a journey into the unknown; that the teacher must know something of this landscape; that both teacher and learner engage in a shared endeavour; and that bothare changed through this shared experience... herein lies the excitement of the 'new sciences': they challenge us to plan in ways that more closely align with human action and interaction and less with machine-like, behaviouristic principles. (Karpiak 2000: 38, 40)

In Mullen and Kochan's (2000) study of transformation through collaborative educational networks, this type of learning became a synergistic relationship between the organization and the individual. Moreover, Mullen and Kochan (2000: 194-195) highlight the feelings of individual empowerment with the comment of one participant: 'We are receiving a boost in enthusiasm and energy from being part of something bigger than what we are individually as people, as professionals, and as an institution'.

A potentially negative bifurcation can emerge here for educational leaders, as Pascale, Millemann and Gioja (2000) note that encouraging these types of synergistic relationships places leaders at a higher risk of organizational criticism. This occurs because we have taken an approach where by we foster hierarchy-breaking relationships. Teachers and administrators can prevent these feelings among colleagues from leading to runaway chaos, however, by incorporating a holistic and systemic-process view of human interaction. Equally, self-perceived visions of leadership failure begin to become less important when teachers and administrators change their views about negative feedback loops that focus so heavily on trying to control and predict outcomes. Instead, educational leaders can shift their emphasis towards a mentoring role that promotes more positive feedback loops, self-organization, and bounded instability.

Learning, personal growth, and professional development are woven into the fabric of everyday life, inseparable from what we say and how we say it. When a philosophy such as this is deeply embedded into the psyches of individual managers, managerial communication becomes less about content or technique and more about relationship building between individuals. (Carter, 2002: 22)

As a result, the work of a dissipative educational system becomes a shared experience, and leaders, therefore, must actively seek out mentoring relationships that help individuals flourish and grow in a transformative environment.

\section{Conclusion}

Dissipative structu.res theory is not intended to be a generalizable theory that is applicable to any educational environment. It does provide us, however, with an epistemological and interpretive framework for studying the natural processes of human interaction, particularly in schools going through transformative change. Within far from equilibrium educational settings, it has been shown that human experience and interaction during the process of change cannot be measured or predicted with any certainty over long periods. Prigogine and Stengers (1984: 312-313) conclude Order out of Chaos:

We know that societies are immensely complex systems involving a potentially enormous number of bifurcations exemplified by the variety of cultures that have evolved in the relatively short span of human history. This leads both to hope and a threat: hope, since even small 
fluctuations may grow and change the overall structure. As a result, individual activity is not doomed to insignificance. On the other hand, this is also a threat, since in our universe the security of stability and permanent rules seem gone forever.

This challenges some of our basic assumptions about the control mechanisms of classical mechanics that typically define our organizational structures, planning efforts, and externally proscribed curriculum.

Harvard Business professor John Seely Brown argues: 'It's never enough to just tell people about some new insight. Rather, you have to get them to experience it in a way that evokes its power and possibility' (Brown 2002: 6). Prigogine has reinforced that, for transformational experiences to occur in education, we must all be actively involved in the process of change, not just organizationally, but also individually. This article shows that dissipative structures theory provides us with both the philosophical and leadership framework to break down traditional hierarchies in education and begin a new process of human-centred self-organization in our schools and colleges. Moreover, an interpretive view of dissipative structures theory helps us analyse and describe the metaphorical significance of our connectedness to the natural world. So it is; the future is not certain. Yet when we view educational settings going through change with a dissipative systems lens, we are able to substitute our objective knowledge of deterministic certainty with a new 'feeling of qualified hope' (Prigogine and Stengers 1984: 313).

\section{References}

Ackoff, R. L. (1981) Creating the Corporate Future: Plan or be Planned For (New York: John Wiley \& Sons).

Ackoff, R. L. (1994) The Democratic Corporation: A Radical Prescription for Recreating Corporate America and Rediscovering Success (New York: Oxford University Press).

Applegate, .L Douglas, M., Gursel, Y., I-Iumer, P., Seirz, C. and Sussman, G. J. (1985) A digital orrery, IEEE Transactions on Computers, C-34(9), 822-831.

Applegate, J., Douglas, M., Gursel, Y. and Sussman, G.J. (1986) The outer solar system for 200 million years, Astronomical Journal, 92, 176--194.

Aram, E. and Noble, D. (1999) Educating prospective managers in the complexity of organizational life. Management Learning, 30(3), 321-342.

Ashby W. R. (1966/1956) . An Introduction to Cybernetics (New York: John Wiley \& Sons, Inc.).

Bass, B. M. (1998) Transformational Leadership: Industrial, Military, and Educational Impact (Mahwah, NJ; Lawrence Erlbaum Associates, Inc.)

Becher, T. and Trowler, P. R. (2001) Academic Tribes and Territories: Intellectual Enquiry and the Culture of Disciplines (Buckingham: Open University Press). 
von Bertalanffy, L. (1973/1968) General System Theory: Foundations, Development, Applications (Revised Edn) (New York: George Braziller, Inc).

Birnbaum, R. (2000) Management Fads in Higher Education: Where They Come From, What They Do, Why They Fail (San Francisco: Jossey-Bass).

Blair, B.G. (1993) What does chaos theory have to offer educational administration? Journal of School Leadership, 3, 579-596.

Breu, K. and Benwell, M. (1999) Modelling individual transition in the context of organizational transformation. Journal of Management Development, 18(6), 496-520.

Brown, J. S. (2002) Research that reinvents the corporation. Harvard Business Review, 80(8), 312.

Burns, J.M. (2003) Transforming Leadership: A New Pursuit of Happiness (New York: Atlantic Monthly Press).

Burns, J. M. (1979) Leadership (New York: Harper \& Row).

Carr-Chellman, A. A, (2000) The new sciences and systemic change in education. Educational Technology (January-February), 28-37.

Carter, T. J. (2002) The importance of talk to midcareer women's development: a collaborative inquiry. The Journal of Business Communication, 39(1), 55-91.

Checkland, P. (1999) Soft Systems Methodology: A 30-Year Retrospective (New York: John Wiley \& Sons, Ltd).

Christensen, T. Laegreid, P. and Wise, L. (2002) Transforming administrative policy. Public Administration, 80(1), 153-178.

Doll, W. E., Jr. (1986) Prigogine: a new sense of order, a new curriculum. Theory Into Practice, 25(1),10-16.

Doll, W. E., Jr. (April 1987) Foundations for a post-modern curriculum. Paper presented at the Annual Meeting of the American Educational Research Association, Washington, D.C.

Doll, W. E., Jr. (1993) A Post-modern Perspective on Curriculum (New York: Teachers College Press).

Fleener, M. J. (April 1995) Dissipative structures and educational contexts: transforming schooling for the 21st century. Paper presented at the Annual Meeting of the American Educational Research Association, San Francisco, CA.

Fleener, M. J. (2002) Curriculum Dynamics: Recreating Heart (New York: Peter Lang Publishing, Inc.). 
Friedman, A. A. (2004) Beyond mediocrity: transformational leadership within a transactional framework. International Journal of Leadership in Education, 7(3), 203-224.

Fullan, M. (2001) Leading in a Culture of Change (San Francisco: Jossey-Bass).

Gale, T. and Densmore, K. (2003) Democratic educational leadership in contemporary times. International Journal of Leadership in Education, 6(2), 119-136.

Gemmill, G. and Smith, C. (1985) A dissipative structure model of organization transformation, Human Relations, 38(8), 751-766.

Gleick, J. (1987) Chaos: Making a New Science (New York: Penguin).

Goeppinger, A. (2002) Commentary, the fallacies of our reality: a deconstructive look at community and leadership. International Journal of Leadership in Education, 5(1), 7783.

Jantsch, E. (1981) The Evolutionary Vision: Toward a Unifying Paradigm of Physical, Biological, and Sociocultural Evolution (Boulder: Westview Press for the American Association for the Advancement of Science).

Jenner, R. (1998) Dissipative enterprises, chaos, and the principles of lean organizations. Omega, International Journal of Management Science, 26(3), 397-407.

Karpiak, I. E. (2000) Evolutionary theory and the 'new sciences': rekindling our imagination for transformation. Studies in Continuing Education, 22(1), 29-44.

Karpov, E., Prigogine, I., Petrosky, T. and Pronko, G. (2000) Friedrich’s model with virtual transitions. Exact solution and indirect spectroscopy. Journal of Mathematical Physics, 41(1), 118-131.

Lakoff, R. T. (1992) Talking Power: The Politics of Language (New York: Basic Books).

Lichtenstein, B. B. (2000) Self-organized transitions: a pattern amid the chaos of transformative change. Academy of Management Executive, 14(4), 128-131.

MacIntosh, R. and MacLean, D, (1999) Conditioned emergence: a dissipative structures approach to transformation. Strategic Management Journal, 20(4), 297-316.

MacIntosh, R. and MacLean, D. (2001) Conditioned emergence: researching change and changing research. International Journal of Operations and Production Management, 21 (10), 1343-1357.

Maturna, H. and Varela, F. (1980) Autopoiesis and Cognition (Dordrecht: D. Reidel Publishing Company). 
Moos, L. (2003) Educational leadership: leadership for/as Bildung? International Journal of Leadership in Education, 6(1), 19-33.

Mullen, C. A. and Kochan, F. K. (2000) Creating a collaborative leadership network: an organic view of change. International Journal of Leadership in Education, 3 (3), 183-200.

Nadler, D. A., Shaw, R. B. and Walton, A. E. (1995) Discontinuous Change: Leading Organizational Transformation (San Francisco: Jossey-Bass).

Newman, K. L. (2000) Organizational transformation during institutional upheaval. Academy of Management Review, 25(3), 602-619.

Nicolis, G. and Prigogine, I. (1989) Exploring Complexity: An Introduction (New York: W. H. Freeman and Company).

O’Sullivan, E. (1999) Transformative Learning: Educational Vision for the 21st Century (New York: St. Martin's Press).

Pascale, R. T., Millemann, M. and Gioja, L. (2000) Surfing the Edge of Chaos: The Laws of Nature and the New Laws of Business (New York: Crown Business).

Peterson, I. (1993) Newton's Clock: Chaos in the Solar System (New York: W. H. Freeman and Company).

Prigogine, I. (1961) On the motion of a charged particle. Journal of Nuclear Energy, Part C Plasma Physics, 2(1), 184-187.

Prigogine, I. (1967) Thermodynamics of Irreversible Processes (New York: John Wiley \& Sons).

Prigogine, I. (1980) From Being to Becoming: Time and Complexity in the Physical Sciences (San Francisco: W. H. Freeman and Company).

Prigogine, I. (1997) The End of Certainty: Time, Chaos, and the New Laws of Nature (New York: The Free Press).

Prigogine, I. (2000) The future is not given, in society or nature. NPQ: New Perspectives Quarterly, 17(2), 35-37.

Prigogine, I. and Stengers, I. (1984) Order Out of Chaos: Man's New Dialogue with Nature (New York: Bantam Books, Incorporated).

Rothman, T. (1997) Irreversible differences. The Sciences, July/August, 26-31.

Sawada, D. and Caley, M. T. (1985) Dissipative structures: new metaphors for becoming in education. Educational Researcher, 14(3), 13-19. 
Schwarz, E. (1997) Toward a holistic cybernetics: from science through epistemology. Cybernetics \& Human Knowing: A Journal of Second-Order Cybernetics and Cyber Semiotics, 4(1), 17-50.

Senge, P. M. (1990) The Fifth Discipline: The Art and Practice of the Learning Organization (New York: Doubleday).

Senge, P. M. (2004) Presence: Human Purpose and the Field of the Future (Cambridge, MA: SoL).

Smith, C. and Comer, D. (1994) Self-organization in small groups: a study of group effectiveness within non-equilibrium conditions. Human Relations, 47(5), 553-581.

Sussman, G. J. and Wisdom, J. (1988) Numerical evidence that the motion of Pluto is chaotic. Science, 241(22 July), 433.

Sussman, G. J. and Wisdom, J. (1992) Chaotic evolution of the solar system. Science, 257.

Stacey, R. D. (1992a) Managing Chaos: Dynamic Business Strategies in an Unpredictable World (London: Kogan Page).

Stacey, R. D. (1992b) Managing the Unknowable: Strategic Boundaries Between Order and Chaos in Organizations (San Francisco: Jossey-Bass).

Stacey, R. D. (2003) Complexity and Group Processes: A Radically Social Understanding of Individuals (New York: Brunner-Routledge).

Tarule, J. M. (1997) A letter to Paulo Freire. In P. Freire, J. W. Fraser, D. Macedo, T. McKinnon and W. T. Stokes (eds) Mentoring the Mentor: A Critical Dialogue with Paulo Freire (Vol. 60) (New York: Peter Lang).

Touma, J. and Wisdom, J. (1993) The chaotic obliquity of Mars. Science, 259(5099), 1294-1297.

Van Olffen, W., Romme, A. and Georges, L. (1995) The role of hierarchy in self-organizing systems. Human Systems Management, 14, 199-206.

Waldrop, M. M. (1992) Complexity: The Emerging Science at the Edge of Order and Chaos (New York: Simon \& Schuster).

Wheatley, M. J. (1994) Leadership and the New Science: Learning about Organization from an Orderly Universe (San Francisco: Berrett-Koehler Publishers, Inc.).

Wisdom, J. (1998) A Brief Introduction to Chaos in the Solar System. Available online at: http:// geosys.mit.edu/-solar/text/short.html (accessed 15 December 2003).

Yukl, G. A. (2002) Leadership in Organizations (5th edn) (Upper Saddle River, NJ: PrenticeHall). 